\title{
Nutrient Recovery by Solid-Liquid Separation and Methane Productivity of Solids
}

\author{
H. B. Møller, J. D. Hansen, C. A. G. Sørensen
}

\begin{abstract}
Solid-liquid separation of manure is a method to produce nutrient and dry matter rich fractions with higher volumetric methane potential than that of the original liquid manure. Centrifugation and chemical precipitation and flocculation are efficient options for such separation. Centrifugation efficiency depends on factors such as manure type, $G$-force, and dewatering volume, while chemical precipitation and flocculation depend on the amount and type of chemicals and polymers used. We assess all these factors in this study. The methane yields of the solids from centrifugation and precipitation were assessed by batch digestion. Dewatering volume and $G$-force had great influence on separation efficiency and on the chemical composition of the solids. Centrifugation transferred increasing amounts of nutrients and dry matter to the solid fraction as gravitational force increased to approximately 2200G. However, increasing gravitational force beyond $2047 G$ did not significantly improve separation efficiency. The quantity of solids and separation efficiency of dry matter and nutrients varied for different manure types. Separation efficiencies for total $N$ and dry matter greatly depended on the manure's dry matter content, while separation efficiency for total $P$ was little affected by the same factors. Because different manure types were used for the tests with precipitation and flocculation, it was impossible to determine the effect of changing the chemicals. However, the separation efficiencies achieved for $N$ and $P$ were higher than those achieved with centrifuged manure of the same dry matter content. The methane yield from the solids separated by chemical precipitation and flocculation were significantly higher than the yield from centrifuged solids. The yields from the solids produced by centrifugation of pig manure were 161 to $186 \mathrm{~L} \mathrm{CH}_{4} / \mathrm{kg} \mathrm{VS}$ compared to $253 \mathrm{~L} \mathrm{CH}_{4} / \mathrm{kg} \mathrm{VS}$ from centrifuged dairy cow manure, while the yields from the solids produced by coagulation and flocculation were 392 to $404 \mathrm{~L} \mathrm{CH}_{4} / \mathrm{kg} \mathrm{VS}$.
\end{abstract}

Keywords. Biogas potential, Separation efficiency, Slurry separation.

$\mathrm{L}$ arge quantities of pig and cattle slurry are produced in Denmark (Poulsen et al., 2001). In Denmark, as in other western European countries, livestock farming is increasingly specialized, leading to a reduction in the number of farms. At the same time, specialization in livestock production has led to the concentration of animals in restricted areas on large farms, a pattern found throughout Europe (Burton and Turner, 2003). Animal manure contains large amounts of organic matter and nutrients, but because of their low concentration in liquid manure, it is difficult to recover the energy and nutrients. Slurry separation is a key process in nutrient recovery strategies (Møller et al., 2000, 2002). Slurry separation is traditionally done either as a post-treatment after anaerobic digestion or independently, although it could also be used as a pre-treatment to improve the volumetric methane potential. Anaerobic digestion is a key process in any energy recovery strategy. Because of the low organic matter concentration of liquid manure, however, digestion is only economic in large-scale co-diges-

Submitted for review in July 2005 as manuscript number SE 5979; approved for publication by the Structures \& Environment Division of ASABE in November 2006.

The authors are Henrik B. Møller, Researcher, Scientist, Jesper D. Hansen, Student, and Claus A. G. Sørensen, ASABE Member Engineer, Senior Scientist, Department of Agricultural Engineering, Danish Institute of Agricultural Sciences, Horsens, Denmark. Corresponding author: Henrik B. Møller, Department of Agricultural Engineering, Danish Institute of Agricultural Sciences, 8700 Horsens, Denmark; phone: +45-8999-3043; fax: +45-8999-3100; e-mail: henrikb.moller@ agrsci.dk. tion plants if liquid manure is co-digested with wastes of high organic matter concentration (Nielsen et al., 2002). However, if a dry matter rich fraction can be produced by solid-liquid separation, digestion of the solid part might improve the economic performance of plants.

When animal manure is physically separated using centrifuges or chemical treatment (addition of coagulants and flocculants) in combination with screening, liquid and solid fractions are produced, the latter containing a higher concentration of dry matter and nutrients than the original manure (Zhang and Lei, 1998; Møller et al., 2000, 2002). Different separation methods produce very different results in transferring dry matter and nutrients to the solid fraction (Møller et al., 2000), but few studies have examined the performance of decanting centrifuges when the operational variables are changed. Several studies have been done to optimize the amounts and types of coagulant and flocculant for separation efficiency (Krumpelman et al., 2005; Timby et al., 2004; Zhang and Lei, 1998), but they have mainly considered flushed dairy manure. The tests of chemical treatment in the present study are done merely so the results can be compared with those obtained with a decanting centrifuge, and to be able to compare the methane yields during anaerobic digestion of the solids produced by the two different technologies. Popular metal coagulants such as $\mathrm{Al}$ and $\mathrm{Fe}$ have been successfully used in combination with polyacrylamides (PAMs), especially high-charge-density cationic polymers (Krumpelman et al., 2005). Alum $\left(\mathrm{Al}_{2}\left(\mathrm{SO}_{4}\right)_{3}\right)$ and $\mathrm{Fe}_{2}\left(\mathrm{SO}_{4}\right)_{3}$ were used as coagulants in this experiment, and PAM (Optifloc C6260) was used as the flocculant. 
An advantage of separation is that it produces solids that can be transported more economically to centralized anaerobic digestion plants. This enables the transport of excess phosphate from high-density animal production areas to areas of phosphate demand. The volumetric methane production of manure can be increased significantly by solid-liquid separation (Møller et al., 2002) that produces solid fractions of high VS concentration; however, some of the VS will still remain in the liquid fraction. If only the solid fraction is used as a substrate for anaerobic digestion, it is important that the separation units be efficient at transferring dry matter to the solid fraction. Møller et al. (2004) found that chemical precipitation, combined with screening and centrifugation, was an efficient method for transferring VS to a solid fraction.

This study assesses the influence of manure type, G-force, and dewatering volume on the separation of nutrients and solids when using a decanting centrifuge. We also compare the efficiency of centrifugation with that of coagulation and flocculation, and finally assess the methane yield from the solids produced by both centrifugation and chemical treatment when digested anaerobically.

\section{Materials AND Methods \\ Analytical Procedures}

Total nitrogen (TN) was analyzed using the Kjeldahl standard method (APHA, 1995) and a Kjell-Foss 16200 autoanalyzer (Foss Electric, Hillerød, Denmark). Dry matter (DM) was determined after drying at $105^{\circ} \mathrm{C}$ for $24 \mathrm{~h}$. Volatile solids (VS) was measured in accordance with standard methods (APHA, 1995). Total phosphorus (TP) was analyzed colorimetrically using a Spectronic 1001 UV-VIS spectrophotometer (Bausch \& Lomb) after dry ashing, solubilization in acid, and a coloring reaction with ammonium molybdate vanadate. Ammonium $\left(\mathrm{NH}_{4}{ }^{+}\right)$in the slurry was analyzed using a QuickChem 4200 flow injection analyzer (Lachat Instruments, Milwaukee, Wisc.). Slurry pH was determined with a $\mathrm{pH}$ meter (Radiometer A/S, Copenhagen, Denmark). $\mathrm{K}, \mathrm{Mg}, \mathrm{Cu}, \mathrm{S}$ and $\mathrm{Ca}$ were analyzed by ICP technology (Optima 2000DV, Perkin Elmer) after drying and destruction with $\mathrm{H}_{2} \mathrm{NO}_{3}$ in an autoclave.

In the tests with centrifugation and chemical coagulation/ flocculation, respectively 20 to $40 \mathrm{~m}^{3}$ and 10 to $20 \mathrm{~m}^{3}$ of manure were subjected to separation.

\section{Full-Scale Separation Tests and Separation EFFICIENCY}

A Pieralisi Jumbo 3 (Italy) decanter centrifuge was used during the tests (fig. 1). In it, the raw slurry is subjected to considerable centrifugal force in a high-velocity rotating drum, typically rotating at 2000 to $4000 \mathrm{rpm}$. During this process, the particle components of the slurry sediment move toward the periphery of the drum where they can subsequently be removed by a rotating screw. This well-tested technology has been used in both industrial and municipal sewage treatment; in recent years, experience has been gained in using the technology with manure slurry as well (Møller et al., 2000, 2002).

The performance of a decanting centrifuge depends on factors such as the G-force, dewatering volume, and retention time. The term G-force or G-value (Møller et al., 2002) is frequently used to define the force acting on the solids: it is the multiple of the gravitational constant obtained in the centrifuge. An approximate formula for calculating the G-force in $G$ (Vanderbeken, 2005) at the drum periphery is:

$$
G=\frac{n^{2} \times \theta}{1800}
$$

where $n$ is the drum speed (rpm), and $\theta$ is the drum's maximum inner diameter $(\mathrm{m})$, which is $0.470 \mathrm{~m}$ in the Jumbo 3 . Consequently, the centrifugal acceleration or G-value will increase with drum diameter and speed. The dewatering volume of a decanter is considered to be the total volume of the liquid zone in the cylindrical part of the drum. This volume may change in relation to the weir plate diameter. For the Pieralisi Jumbo 3 decanter, weir plate standard diameters are $310,300,285,280$, and $273 \mathrm{~mm}$. During the "standard" tests performed with manure types 1 a to $4 \mathrm{c}$ (table 1 ), the centrifuge rotated at $2900 \mathrm{rpm}$, thus causing a G-force of $2196 \mathrm{G}$. During this "standard" testing, the weir plate diameter was $280 \mathrm{~mm}$ and the differential speed of the screw was on average $80 \mathrm{rpm}$ slower than the speed of the drum, but the diameter was changed during some of the tests to measure the influence on performance and on separation efficiency. The G-force therefore changed during some of the tests.

The retention time $(R)$ in seconds can be calculated as:

$$
R=3600 \times \frac{\text { Dew.Vol }}{Q}
$$

where $Q$ is the effluent input $(\mathrm{L} / \mathrm{h})$ and Dew. Vol is the dewatering volume $(179 \mathrm{~L}$, based on $273 \mathrm{~mm}$ diameter weir

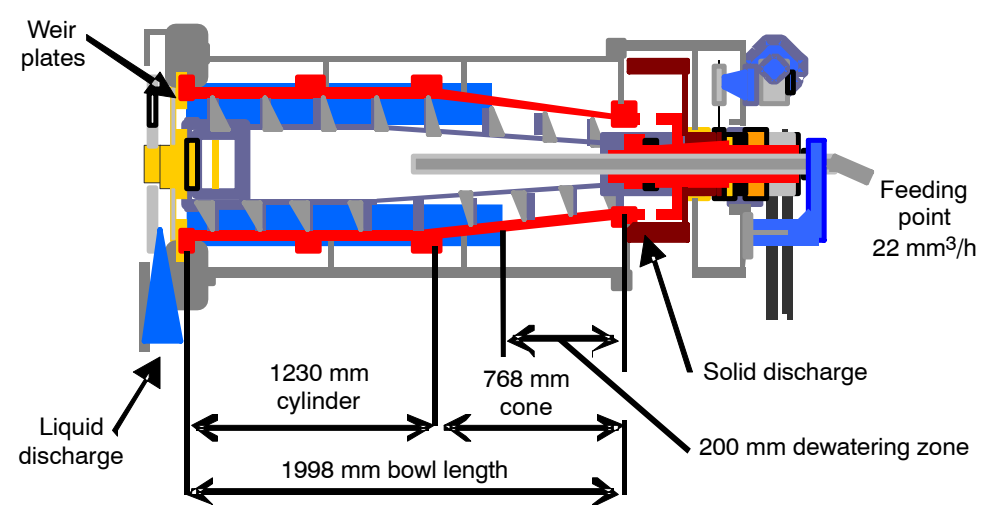

Figure 1. Cross-section of a Pieralisi Jumbo 3 decanting centrifuge with dimensions. 
plates). The retention time is the length of time that the liquid remains in the bowl before discharge. For a given input $(Q)$ and no change in screw rpm, the retention time will change when the weir plate diameter is modified to change the dewatering volume, with a smaller weir plate diameter increasing the retention time. Longer retention time will produce more efficient solid-liquid separation. With an input of $Q=22 \mathrm{~m}^{3} / \mathrm{h}$ and a dewatering volume of $179 \mathrm{~L}$, the retention time will be 29 s. During the "standard" testing, the input to the centrifuge varied between 10 and $25 \mathrm{~m}^{3} / \mathrm{h}$, where the lowest capacity was in cattle manure and the highest capacity in pig and digested manure. In one test (HF), the capacity was increased to $40 \mathrm{~m}^{3} / \mathrm{h}$.

The Kemira Miljoe separator (Esbjerg, Denmark) had a capacity of approximately $8 \mathrm{~m}^{3} / \mathrm{h}$ and consists of three flocculation chambers $(700 \mathrm{~L}$ each) in which added chemicals are mixed to form new compounds; this alters the physical state of the dissolved and suspended solids and facilitates their removal by a belt press. The dry matter was coagulated and flocculated, resulting in 2 to $10 \mathrm{~mm}$ flocs, and the dry matter was then removed and dewatered on a $4 \mathrm{~m}$ belt with $2 \mathrm{~mm}$ screen size and finally dewatered in a screw press with $1 \mathrm{~mm}$ screen size. The belt was continuously cleaned by washing with water. Alum, $\left(\mathrm{Al}_{2} \mathrm{SO}_{4}\right)_{3} \cdot 18 \mathrm{H}_{2} \mathrm{O}$, or $\mathrm{Fe}_{2} \mathrm{SO}_{4}$ was used as a coagulant $\left(0.5 \mathrm{~kg} / \mathrm{m}^{3}\right.$ pig slurry $)$ and a cationic polymer, Optifloc C6260, $40 \%$ active $\left(0.2 \mathrm{~L} / \mathrm{m}^{3}\right.$ manure), was used to agglomerate the coagulated particles.

The rate at which manure was added to the centrifuge was measured with a magnetic-inductive flowmeter (Danfoss Mag 3100, Sønderborg, Denmark). The centrifuge produced solid and liquid fractions; the solids were measured by collecting the material in containers and weighing the containers after the separation tests, while the liquid was measured using the same model of magnetic-inductive flowmeter. The manure was stirred immediately before each test, and manure samples were taken three to six times during the test. Representative samples of the solid and liquid fractions were taken five times during a separation experiment. All samples were stored at $-18^{\circ} \mathrm{C}$ until analysis.

The amount of water added to the Kemira Miljoe separator was determined by calculating the dilution factor. This was done by comparing the potassium concentrations in the raw manure and in the liquid after separation, since potassium is regarded as completely soluble. The use of water was found to range between 100 and $500 \mathrm{~L} / \mathrm{m}^{3}$ of manure. The use of water has since been reduced by using the liquid from separation for cleaning the belt.

Separation efficiency is defined as the total mass recovery of solids and nutrients in the solid fraction, as a proportion of the total input of solids or nutrients (Svarovsky, 1985):

$$
E_{1}=\frac{U \times M_{c}}{Q \times S_{c}}
$$

where $E_{1}$ is the index for simple separation efficiency, $U$ is the quantity of the solid fraction in weight $(\mathrm{kg} / \mathrm{kg}$ slurry treated), $M_{c}$ is the concentration of the components (DM, TP, and $\mathrm{TN})$ in the solid fraction $(\mathrm{g} / \mathrm{kg}), Q$ is the amount of raw slurry treated $(\mathrm{kg})$, and $S_{c}$ is the concentration of the components in the slurry $(\mathrm{g} / \mathrm{kg})$.

\section{Gas Production}

The ultimate methane yield $\left(B_{0}\right)$ was determined in a batch experiment. The experiments were performed in $1100 \mathrm{~mL}$ infusion bottles, which were closed with butyl rubber stoppers, sealed with aluminum crimps, and incubated at $35^{\circ} \mathrm{C} \pm 0.5^{\circ} \mathrm{C}$, after flushing with $\mathrm{N}_{2}$. The test media were frozen until used in the batch. Inoculum from a farm-scale biogas plant was used; it had been stored at $35^{\circ} \mathrm{C}$ for two weeks before testing to ensure that most of the remaining methane production was complete. Each test medium was digested in triplicate, and the gas production was subtracted from the gas produced by the control medium (inoculum and water only). The volume of gas produced was measured by connecting the infusion vessel to a gas collection bag, and using a large syringe to measure the volume of gas, as described by Steed and Hashimoto (1994). The gas samples were analyzed for $\mathrm{CO}_{2}$ and $\mathrm{CH}_{4}$ content using gas chromatography. $\mathrm{CH}_{4}$ was measured on a Hewlett Packard 5890 series II gas chromatograph equipped with an electron capture detector and a flame ionization detector. Methane was isolated using a $1.83 \mathrm{~m} \times 3.1 \mathrm{~mm}$ column with Poropak $\mathrm{N} 80 / 100$; He was used as the carrier gas at $30 \mathrm{~mL} / \mathrm{min}$, and the injection port, oven, and detector temperatures were $110^{\circ} \mathrm{C}, 40^{\circ} \mathrm{C}$, and $270^{\circ} \mathrm{C}$, respectively. $\mathrm{CO}_{2}$ was measured using a Varian 3350 gas chromatograph equipped with a ther-

\begin{tabular}{|c|c|c|c|c|c|c|c|c|c|}
\hline Manure Type & $\begin{array}{l}\text { Manure } \\
\text { ID }\end{array}$ & $\begin{array}{c}\text { No. of } \\
\text { Manures }\end{array}$ & $\begin{array}{l}\mathrm{DM} \\
(\%)\end{array}$ & $\begin{array}{c}\mathrm{TN} \\
(\mathrm{g} / \mathrm{kg})\end{array}$ & $\begin{array}{c}\mathrm{NH}_{4}-\mathrm{N} \\
(\mathrm{g} / \mathrm{kg})\end{array}$ & $\begin{array}{c}\mathrm{TP} \\
(\mathrm{g} / \mathrm{kg})\end{array}$ & $\begin{array}{c}\mathrm{K} \\
(\mathrm{g} / \mathrm{kg})\end{array}$ & $\begin{array}{c}\mathrm{Mg} \\
(\mathrm{g} / \mathrm{kg})\end{array}$ & $\begin{array}{c}\mathrm{Cu} \\
(\mathrm{g} / \mathrm{kg})\end{array}$ \\
\hline \multicolumn{10}{|l|}{ Tests with decanting centrifuge } \\
\hline Pig manure, fattening (average) & $1 \mathrm{a}-1 \mathrm{~h}$ & 8 & $5.1(2.4)$ & $5.4(1.2)$ & $3.9(0.7)$ & $1.1(0.6)$ & $3.3(0.6)$ & 0.75 & 0.02 \\
\hline Sow manure (average) & $2 a-2 f$ & 6 & $4.0(2.4)$ & $4.0(0.8)$ & $2.7(0.4)$ & $1.0(0.7)$ & $2.0(0.7)$ & 0.31 & 0.02 \\
\hline Digested pig manure (average) & $3 a-3 c$ & 3 & $3.2(2.5)$ & $4.1(0.6)$ & $3.8(0.7)$ & $1.4(0.9)$ & $1.9(0.3)$ & 0.49 & 0.017 \\
\hline Dairy cow manure (average) & $4 a-4 c$ & 3 & $7.0(0.8)$ & $4.2(0.4)$ & $2.2(0.3)$ & $0.8(0.1)$ & $3.0(0.6)$ & 0.60 & 0.005 \\
\hline \multicolumn{10}{|l|}{ Pig manure: } \\
\hline G-force and weir plate diameter experiment & 5 & 1 & $6.8(0.6)$ & $5.79(0.2)$ & $4.62(0.1)$ & $1.32(0.1)$ & $3.92(0.1)$ & 0.76 & 0.01 \\
\hline G-force experiment & 6 & 1 & 8.9 & 6.86 & 4.56 & 2.3 & 5.4 & 0.75 & 0.02 \\
\hline \multicolumn{10}{|l|}{ Tests with chemical precipitation } \\
\hline Pig manure (polymer) & 7 & 1 & 1.21 & 2.45 & 2.15 & 0.32 & 1.6 & & \\
\hline Pig manure (polymer $\left.+\mathrm{Fe}_{2}\left(\mathrm{SO}_{4}\right)_{3}\right)$ & 7 & 1 & 1.21 & 2.45 & 2.15 & 0.32 & 1.6 & & \\
\hline Pig manure (polymer $\left.+\mathrm{Fe}_{2}\left(\mathrm{SO}_{4}\right)_{3}\right)$ & 8 & 1 & 2.08 & 5.27 & 4.28 & 0.29 & 3.1 & & \\
\hline Pig manure (polymer + Alum) & 8 & 1 & 2.08 & 5.27 & 4.28 & 0.29 & 3.1 & & \\
\hline Pig manure (polymer) & 8 & 1 & 2.84 & 4.58 & 4.43 & 0.53 & 2.9 & & \\
\hline Pig manure (polymer + Alum) & 9 & 1 & 4.2 & 4.52 & 3.25 & 0.82 & 2.19 & 0.37 & 0.046 \\
\hline
\end{tabular}


mal conductivity detector. It was equipped with a $1 \mathrm{~m} \times 3.1$ $\mathrm{mm}$ column with a $2 \mathrm{~m} \times 3.1 \mathrm{~mm}$ Haysep R 80/100 molecular sieve. The carrier gas was $\mathrm{He}$ at a flow rate of $30 \mathrm{~mL} / \mathrm{min}$; the oven and detector temperatures were $40^{\circ} \mathrm{C}$ and $150^{\circ} \mathrm{C}$, respectively.

\section{Results AND Discussion}

\section{Mass Balances and Chemical CoMposition}

The chemical characteristics of the pig manure (from sows and fattening pigs), dairy cow manure, and anaerobically digested pig manure used in the standard tests are given in table 1. Manure characteristics are affected by the type of animal, but there is also a significant variation within individual animal categories.

After centrifugation under standard conditions, the quantities of solids and the separation efficiencies for dry matter and nutrients were found to be variable for different manure types (table 2 and fig. 2). The separation efficiencies (\%) were 37 to 68,50 to 83 , and 8 to 33 for DM, TP, and TN, respectively. The separation efficiencies for total $N\left(R^{2}=0.6\right)$ and dry matter $\left(\mathrm{R}^{2}=0.4\right)$ were correlated with the dry matter content of the manure, while the separation efficiency for total $\mathrm{P}\left(\mathrm{R}^{2}=0.0004\right)$ was not significant affected by the dry matter content of the slurry. Møller et al. (2002) found a similar correlation using a different centrifuge (table 3), but the linear regression results were quite different. This indicates that different centrifuges have different separation characteristics. This is important in Denmark, where farmers

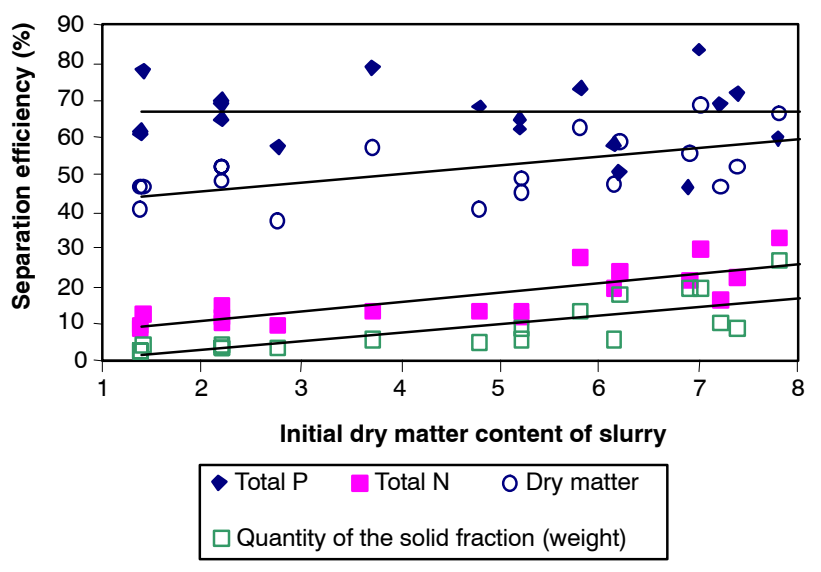

Figure 2. Quantity of the solid fraction in weight ( $U$ in eq. 3), DM, TP, and TN transferred from the manure to the solid fraction during centrifugation (under standard conditions) as a function of dry matter content of untreated slurry. The following linear regression equations were derived from the data: TP: $y=0.08 x+66.059\left(R^{2}=0.0004\right)$; DM: $y=2.29 x+41.824$ $\left(\mathbf{R}^{2}=0.36\right)$; TN: $y=2.51 x+7.134\left(R^{2}=0.66\right)$; quantity of solids: $y=2.3 x-$ $1.54\left(R^{2}=0.6268\right)$.

need a separation efficiency of over $60 \% \mathrm{TP}$ and $20 \% \mathrm{TN}$ to obtain legal permission to increase herd size by $25 \%$ without buying more land (Seadi and Møller, 2003). For TP, it was possible for both centrifuges to achieve $60 \% \mathrm{TP}$, even with very dilute manure, while the Pieralisi Jumbo 3 decanter centrifuge could only remove over $20 \%$ of TN if the DM of the manure was $>5.5 \%$. The Alfa Laval NX 309B-31 centri-

Table 2. Average separation efficiency for the different manure categories subjected to different treatments.

\begin{tabular}{|c|c|c|c|c|c|c|c|c|c|c|c|c|c|c|}
\hline \multirow[b]{2}{*}{$\begin{array}{l}\text { Manure } \\
\text { ID }\end{array}$} & \multicolumn{3}{|c|}{ Decanting Centrifuge } & \multicolumn{11}{|c|}{ Separation Efficiency } \\
\hline & $\begin{array}{l}\text { G-force } \\
(G)\end{array}$ & $\begin{array}{l}\text { Weir Plate } \\
\text { Diameter }\end{array}$ & & $\begin{array}{l}U^{[\mathrm{a}]} \\
(\%)\end{array}$ & $\begin{array}{l}\mathrm{DM} \\
(\%)\end{array}$ & $\begin{array}{l}\text { TN } \\
(\%)\end{array}$ & $\begin{array}{c}\mathrm{NH}_{4}-\mathrm{N} \\
(\%)\end{array}$ & $\begin{array}{c}\mathrm{TP} \\
(\%)\end{array}$ & $\begin{array}{c}\mathrm{K} \\
(\%)\end{array}$ & $\begin{array}{l}\mathrm{Mg} \\
(\%)\end{array}$ & $\begin{array}{l}\mathrm{Cu} \\
(\%)\end{array}$ & $\begin{array}{c}\text { Org. N } \\
(\%)\end{array}$ & $\begin{array}{l}\mathrm{Ca} \\
(\%)\end{array}$ & $\begin{array}{c}\mathrm{S} \\
(\%)\end{array}$ \\
\hline \multirow[t]{2}{*}{1} & 2196 & 280 & Avg: & 9.2 & 51.1 & 16.6 & 9.8 & 70.5 & 8.4 & 79.4 & 23.7 & 39.5 & -- & -- \\
\hline & 2196 & 280 & SD: & 6.0 & 12.4 & 7.7 & 6.6 & 9.4 & 5.8 & 11.5 & 7.9 & 15.7 & -- & -- \\
\hline \multirow[t]{2}{*}{2} & 2196 & 280 & Avg: & 6.6 & 51.8 & 17.1 & 7.4 & 70.0 & 7.7 & 82.1 & 27.9 & 41.3 & -- & -- \\
\hline & 2196 & 280 & SD: & 3.8 & 6.2 & 6.5 & 4.3 & 5.8 & 4.1 & 8.3 & 9.5 & 9.3 & -- & -- \\
\hline \multirow[t]{2}{*}{3} & 2196 & 280 & Avg: & 4.3 & 47.5 & 13.4 & 6.0 & 62.6 & 5.1 & 92.6 & 31.7 & 40.0 & -- & -- \\
\hline & 2196 & 280 & SD: & 1.5 & 0.9 & 5.8 & 2.8 & 5.7 & 1.7 & 2.7 & 12.7 & & -- & -- \\
\hline \multirow[t]{2}{*}{4} & 2196 & 280 & Avg: & 22.5 & 62.7 & 28.7 & 16.1 & 55.2 & 20.7 & 60.0 & 35.4 & 40.5 & -- & -- \\
\hline & 2196 & 280 & SD: & 6.4 & 5.2 & 6.5 & 8.5 & 6.4 & 4.3 & 5.7 & 10.0 & 2.9 & -- & -- \\
\hline 5 & 2196 & 290 & & 12.0 & 62.3 & 21.4 & 9.2 & 76.2 & 11.0 & 90.9 & 23.7 & 51.2 & -- & -- \\
\hline 5 & 2196 & 280 & & 16.0 & 69.1 & 27.3 & 12.6 & 81.2 & 14.3 & 92.9 & 31.9 & 61.1 & -- & -- \\
\hline 5 & 2196 & $270(\mathrm{HF})$ & & 18.7 & 69.7 & 28.9 & 21.0 & 83.1 & 17.9 & 94.8 & 37.6 & 47.9 & -- & -- \\
\hline 5 & 2196 & 270 (LF) & & 26.0 & 70.4 & 35.5 & 26.0 & 81.7 & 25.0 & 94.2 & 39.9 & 61.3 & -- & -- \\
\hline 5 & 1044 & 280 & & 9.6 & 55.5 & 16.8 & 7.4 & 65.4 & 7.7 & 84.2 & 21.8 & 49.6 & -- & -- \\
\hline 5 & 1504 & 280 & & 11.0 & 58.4 & 18.6 & 9.9 & 71.7 & 9.6 & 87.9 & 21.2 & 42.4 & -- & -- \\
\hline 5 & 2196 & 280 & & 16.0 & 69.1 & 27.3 & 12.6 & 81.2 & 14.3 & 92.9 & 31.9 & 61.1 & -- & -- \\
\hline 6 & 2047 & 280 & & 21.8 & 69.4 & 33.5 & 22.3 & 87.2 & 33.0 & 94.6 & 36.2 & 51.9 & 81.3 & -- \\
\hline 6 & 2350 & 280 & & 20.7 & 68.7 & 33.0 & 22.7 & 86.2 & 32.2 & 93.5 & 27.8 & 48.6 & 76.7 & -- \\
\hline \multirow[t]{3}{*}{6} & 2558 & 280 & & 17.6 & 69.3 & 28.6 & 18.0 & 84.5 & 25.8 & 94.2 & 33.9 & 45.9 & 77.2 & 53,5 \\
\hline & \multicolumn{3}{|c|}{ Chemical Precipitation } & & & & & & & & & & & \\
\hline & Coagulate & Floc & late & & & & & & & & & & & \\
\hline 7 & 0 & Optiflo & C6260 & 4.5 & 55.1 & 19.7 & 7.6 & 72.4 & 3.9 & -- & -- & 71.9 & -- & -- \\
\hline 7 & $\mathrm{Fe}_{2}\left(\mathrm{SO}_{4}\right)_{3}$ & Optiflo & C6260 & 6.0 & 55.7 & 24.4 & 8.6 & 74.7 & 5.2 & -- & -- & 80.4 & -- & -- \\
\hline 8 & $\mathrm{Fe}_{2}\left(\mathrm{SO}_{4}\right)_{3}$ & Optiflo & C6260 & 4.5 & 53.8 & 16.1 & 6.6 & 72.6 & 4.5 & -- & -- & 61.8 & -- & -- \\
\hline 8 & $\left(\mathrm{AL}_{2} \mathrm{SO}_{4}\right)_{3}$ & Optiflo & C6260 & 9.5 & 73.3 & 34.5 & 15.3 & 91.3 & 10.4 & -- & -- & 83.4 & -- & -- \\
\hline 8 & 0 & Optiflo & C6260 & 13.0 & 84.4 & 54.3 & 18.3 & 84.6 & 14.0 & -- & -- & 87.5 & -- & -- \\
\hline 9 & $\left(\mathrm{AL}_{2} \mathrm{SO}_{4}\right)_{3}$ & Optiflo & C6260 & 18.0 & 87.0 & 45.1 & 27.7 & 90.2 & 25.6 & 90.8 & 95.7 & 63.1 & 92.9 & 70.0 \\
\hline
\end{tabular}

[a] $U=$ quantity of solid fraction in weight. 
Table 3. Linear regression equations for separation efficiency $(y)$, in terms of dry matter in the manure subjected to separation $(x)$, derived from the data from this study (Pieralisi Jumbo 3) and a previous study (Alfa Laval NX 309B-31; Møller et al., 2002) with a decanting centrifuge.

\begin{tabular}{|c|c|c|c|c|}
\hline & \multicolumn{2}{|c|}{ Pieralisi Jumbo 3} & \multicolumn{2}{|c|}{ Alfa Laval NX 309B-31 } \\
\hline & Linear Regression & $\mathrm{R}^{2}$ & Linear Regression & $\mathrm{R}^{2}$ \\
\hline Quantity of solids & $y=2.3 x-1.54$ & 0.63 & $y=2.665 x-0.6632$ & 0.76 \\
\hline DM & $y=2.29 x+41.824$ & 0.36 & $y=3.3 x+41.824$ & 0.27 \\
\hline $\mathrm{TP}$ & $y=0.08 x+66.059$ & 0.0004 & $y=02.483 x+59.727$ & 0.1 \\
\hline $\mathrm{TN}$ & $y=2.51 x+5.69$ & 0.66 & $y=4.28 x+7.134$ & 0.50 \\
\hline
\end{tabular}

fuge (Møller et al., 2002) removed more than $20 \%$ of TN if the DM of the manure was $>3 \%$. This was mainly because the Pieralisi Jumbo 3 decanter centrifuge produced a solid fraction of considerably higher DM content than that produced by the Alfa Laval NX 309B-31 device, thus transferring less of the dissolved $\mathrm{NH}_{4}{ }^{+}$with the liquid associated with the solids.

The chemical characteristics of the solid fraction after centrifugation (standard conditions) are given in table 4 . The solid fraction showed 6 to 10,9 to 11 , and 2 to 2.9 times higher average concentrations of $\mathrm{DM}$, total $\mathrm{P}$, and total $\mathrm{N}$, respectively, than in untreated pig manure (from sows and fattening pigs) or digested pig manure, while the solid fraction showed $3,2.5$, and 1.2 times higher average concentrations of DM, total $\mathrm{P}$, and total $\mathrm{N}$, respectively, than in untreated dairy cow manure. This clearly indicates that centrifugation efficiently concentrates the DM and total P contents of the solid fraction of pig manure; however, the efficiency with which it concentrates the DM and total P contents of the solid fraction of dairy cow manure is relatively lower. The concentration efficiency for total $\mathrm{N}$ in the solid fraction is relatively low for all manure types because the centrifuge mainly transfers the organic part of the nitrogen to the solid fraction, while most of the dissolved $\mathrm{NH}_{4}{ }^{+}$stays in the liquid (Møller et al., 2002).

With chemical treatment, the quantity of the solids and the separation efficiency for dry matter and nutrients also proved to be variable, depending on the different manure types and coagulants and flocculants (table 2). The separation efficiencies (\%) obtained with chemical precipitation were 55 to 87,72 to 91, and 16 to 45 for DM, TP, and TN, respectively, which were higher efficiencies than achieved with the centrifuge. However, direct comparison between centrifugation and chemical precipitation is not possible since the manure subjected to chemical precipitation had greatly reduced DM content. If the DM values in the two tests had been more comparable, the difference would probably have been greater. The chemical characteristics of the solid fraction after chemical precipitation (under standard conditions) are given in table 4 . The solid fraction showed 5 to $13,4.7$ to 15 , and 2.1 to 3.8 times higher average concentrations of DM, TP, and total N, respectively, than in untreated pig manure; however, the concentration of TP was lower than in the solids resulting from centrifugation, mainly due to lower DM concentration.

Table 4. Composition of the solid fraction after separation of the manure.

\begin{tabular}{|c|c|c|c|c|c|c|c|c|c|c|c|c|}
\hline \multirow[b]{2}{*}{$\begin{array}{l}\text { Manure } \\
\text { ID }\end{array}$} & \multicolumn{3}{|c|}{ Decanting Centrifuge } & \multicolumn{9}{|c|}{ Concentration in Solid Fraction } \\
\hline & $\begin{array}{l}\text { G-force } \\
(G)\end{array}$ & $\begin{array}{l}\text { Weir Plate } \\
\text { Diameter }\end{array}$ & & $\begin{array}{c}\mathrm{DM} \\
(\mathrm{g} / \mathrm{kg})\end{array}$ & $\begin{array}{c}\mathrm{TN} \\
(\mathrm{g} / \mathrm{kg})\end{array}$ & $\begin{array}{c}\mathrm{NH}_{4}-\mathrm{N} \\
(\mathrm{g} / \mathrm{kg})\end{array}$ & $\begin{array}{c}\mathrm{TP} \\
(\mathrm{g} / \mathrm{kg})\end{array}$ & $\begin{array}{c}\mathrm{K} \\
(\mathrm{g} / \mathrm{kg})\end{array}$ & $\begin{array}{c}\mathrm{Mg} \\
(\mathrm{g} / \mathrm{kg})\end{array}$ & $\begin{array}{c}\mathrm{Cu} \\
(\mathrm{g} / \mathrm{kg})\end{array}$ & $\begin{array}{c}\mathrm{Ca} \\
(\mathrm{g} / \mathrm{kg})\end{array}$ & $\begin{array}{c}\mathrm{S} \\
(\mathrm{g} / \mathrm{kg})\end{array}$ \\
\hline \multirow[t]{2}{*}{1} & 2196 & 280 & Avg: & 327 & 10.8 & 4.0 & 9.7 & 3.0 & 5.2 & 0.0909 & -- & -- \\
\hline & 2196 & 280 & SD: & 22 & 1.3 & 1.1 & 1.7 & 0.5 & 1.9 & 0.0559 & -- & -- \\
\hline \multirow[t]{2}{*}{2} & 2196 & 280 & Avg: & 327 & 10.4 & 3.1 & 10.6 & 2.2 & 3.8 & 0.0770 & -- & -- \\
\hline & 2196 & 280 & SD: & 19 & 1.5 & 0.7 & 2.2 & 0.4 & 1.0 & 0.0403 & -- & -- \\
\hline \multirow[t]{2}{*}{3} & 2196 & 280 & Avg: & 326 & 11.9 & 4.7 & 15.3 & 2.2 & 6.5 & 0.0957 & -- & -- \\
\hline & 2196 & 280 & SD: & 10 & 0.9 & 0.5 & 1.2 & 0.1 & 1.1 & 0.0145 & -- & -- \\
\hline \multirow[t]{2}{*}{4} & 2196 & 280 & Avg: & 211 & 5.0 & 1.7 & 1.9 & 3.2 & 1.5 & 0.0080 & -- & -- \\
\hline & 2196 & 280 & SD: & 13 & 0.6 & 0.6 & 0.3 & 0.4 & 0.4 & 0.0017 & -- & -- \\
\hline 5 & 2196 & 290 & & 343 & 11.0 & 3.3 & 8.2 & 3.6 & 5.1 & 0.0250 & -- & -- \\
\hline 5 & 2196 & 280 & & 325 & 10.9 & 3.5 & 7.7 & 3.6 & 4.8 & 0.0270 & -- & -- \\
\hline 5 & 2196 & $270(\mathrm{HF})$ & & 256 & 9.4 & 4.8 & 6.2 & 3.6 & 4.0 & 0.0210 & -- & -- \\
\hline 5 & 2196 & 270 (LF) & & 186 & 8.5 & 4.6 & 3.8 & 3.8 & 2.3 & 0.0170 & -- & -- \\
\hline 5 & 1044 & 280 & & 279 & 10.3 & 3.6 & 6.6 & 3.7 & 4.0 & 0.0210 & -- & -- \\
\hline 5 & 1504 & 280 & & 319 & 10.4 & 4.1 & 7.8 & 3.7 & 4.7 & 0.0240 & -- & -- \\
\hline 5 & 2196 & 280 & & 325 & 10.9 & 3.5 & 7.7 & 3.6 & 4.8 & 0.0270 & -- & -- \\
\hline 6 & 2047 & 280 & & 330 & 11.4 & 4.72 & 12.0 & 6.93 & 4.62 & 0.0363 & 15.18 & -- \\
\hline 6 & 2350 & 280 & & 339 & 12.4 & 5.13 & 12.0 & 7.119 & 4.407 & 0.0339 & 14.238 & -- \\
\hline \multirow[t]{3}{*}{6} & 2558 & 280 & & 410 & 12.1 & 4.74 & 12.0 & 8.2 & 5.33 & 0.04 & 15.99 & 2,501 \\
\hline & \multicolumn{3}{|c|}{ Chemical Precipitation } & & & & & & & & & \\
\hline & Coagulate & Floc & & & & & & & & & & \\
\hline 7 & 0 & Optiflo & 66260 & 164 & 9.5 & 3.0 & 5.0 & 1.2 & -- & -- & -- & -- \\
\hline 7 & $\mathrm{Fe}_{2}\left(\mathrm{SO}_{4}\right)_{3}$ & Optiflo & C6260 & 122 & 8.9 & 2.4 & 3.7 & 1.2 & -- & -- & -- & -- \\
\hline 8 & $\mathrm{Fe}_{2}\left(\mathrm{SO}_{4}\right)_{3}$ & Optiflo & 66260 & 235 & 11.4 & 3.9 & 4.5 & 2 & -- & -- & -- & -- \\
\hline 8 & $\left(\mathrm{AL}_{2} \mathrm{SO}_{4}\right)_{3}$ & Optiflo & C6260 & 261 & 12.7 & 4.0 & 5.0 & 2.1 & -- & -- & -- & -- \\
\hline 8 & 0 & Optiflo & C6260 & 236 & 14.5 & 2.4 & 3.3 & 1.2 & -- & -- & -- & -- \\
\hline 9 & $\left(\mathrm{AL}_{2} \mathrm{SO}_{4}\right)_{3}$ & Optiflo & 66260 & 222 & 9.9 & 3.1 & 3.9 & 2.28 & 1.5 & 0.21 & 9.2 & 1.65 \\
\hline
\end{tabular}


Table 5. Composition of the liquid fraction after separation of the manure.

\begin{tabular}{|c|c|c|c|c|c|c|c|c|c|c|c|c|}
\hline \multirow[b]{2}{*}{$\begin{array}{l}\text { Manure } \\
\text { ID }\end{array}$} & \multicolumn{3}{|c|}{ Decanting Centrifuge } & \multicolumn{9}{|c|}{ Concentration in Liquid Fraction } \\
\hline & $\begin{array}{c}\text { G-force } \\
(G)\end{array}$ & $\begin{array}{l}\text { Weir Plate } \\
\text { Diameter }\end{array}$ & & $\begin{array}{c}\mathrm{DM} \\
(\mathrm{g} / \mathrm{kg})\end{array}$ & $\begin{array}{c}\mathrm{TN} \\
(\mathrm{g} / \mathrm{kg})\end{array}$ & $\begin{array}{c}\mathrm{NH}_{4}-\mathrm{N} \\
(\mathrm{g} / \mathrm{kg})\end{array}$ & $\begin{array}{c}\mathrm{TP} \\
(\mathrm{g} / \mathrm{kg})\end{array}$ & $\begin{array}{c}\mathrm{K} \\
(\mathrm{g} / \mathrm{kg})\end{array}$ & $\begin{array}{c}\mathrm{Mg} \\
(\mathrm{g} / \mathrm{kg})\end{array}$ & $\begin{array}{c}\mathrm{Cu} \\
(\mathrm{g} / \mathrm{kg})\end{array}$ & $\begin{array}{c}\mathrm{Ca} \\
(\mathrm{g} / \mathrm{kg})\end{array}$ & $\underset{(\mathrm{g} / \mathrm{kg})}{\mathrm{S}}$ \\
\hline \multirow[t]{2}{*}{1} & 2196 & 280 & Avg: & 27.6 & 4.9 & 3.8 & 0.3 & 3.4 & 0.13 & 0.026 & -- & -- \\
\hline & 2196 & 280 & SD: & 10.5 & 0.9 & 0.9 & 0.1 & 0.7 & 0.09 & 0.018 & -- & -- \\
\hline \multirow[t]{2}{*}{2} & 2196 & 280 & Avg: & 20.7 & 3.3 & 2.6 & 0.3 & 1.8 & 0.06 & 0.015 & -- & -- \\
\hline & 2196 & 280 & SD: & 9.4 & 0.7 & 0.4 & 0.2 & 0.7 & 0.04 & 0.011 & -- & -- \\
\hline \multirow[t]{2}{*}{3} & 2196 & 280 & Avg: & 16.3 & 3.5 & 3.4 & 0.4 & 1.9 & 0.03 & 0.012 & -- & -- \\
\hline & 2196 & 280 & SD: & 5.8 & 0.4 & 0.4 & 0.3 & 0.5 & 0.02 & 0.009 & -- & -- \\
\hline \multirow[t]{2}{*}{4} & 2196 & 280 & Avg: & 37.7 & 3.9 & 2.3 & 0.5 & 3.2 & 0.32 & 0.004 & -- & -- \\
\hline & 2196 & 280 & SD: & 3.2 & 0.3 & 0.3 & 0.1 & 0.7 & 0.07 & 0.001 & -- & -- \\
\hline 5 & 2196 & 290 & & 28.4 & 5.5 & 4.5 & 0.35 & 4 & 0.07 & 0.011 & -- & -- \\
\hline 5 & 2196 & 280 & & 27.7 & 5.5 & 4.6 & 0.34 & 4.1 & 0.07 & 0.011 & -- & -- \\
\hline 5 & 2196 & $270(\mathrm{HF})$ & & 25.6 & 5.3 & 4.2 & 0.29 & 3.8 & 0.05 & 0.008 & -- & -- \\
\hline 5 & 2196 & $270(\mathrm{LF})$ & & 27.5 & 5.4 & 4.6 & 0.30 & 4 & 0.05 & 0.009 & -- & -- \\
\hline 5 & 1044 & 280 & & 28.1 & 0.0 & 4.6 & 0.4 & 4.3 & 0.0800 & 0.011 & -- & -- \\
\hline 5 & 1504 & 280 & & 28.1 & 0.0 & 4.6 & 0.4 & 4.3 & 0.0800 & 0.011 & -- & -- \\
\hline 5 & 2196 & 280 & & 27.7 & 0.0 & 4.6 & 0.3 & 4.1 & 0.0700 & 0.011 & -- & -- \\
\hline 6 & 2047 & 280 & & 40.4 & 6.3 & 4.58 & 0.49 & 3.9188 & 0.0727 & 0.017776 & 0.9696 & -- \\
\hline 6 & 2350 & 280 & & 40 & 6.56 & 4.55 & 0.5 & 3.9091 & 0.0806 & 0.022971 & 1.1284 & -- \\
\hline \multirow[t]{3}{*}{6} & 2558 & 280 & & 39 & 6.45 & 4.6 & 0.47 & 5.031 & 0.0697 & 0.017028 & 1.0062 & 0,4644 \\
\hline & \multicolumn{3}{|c|}{ Chemical Precipitation } & & & & & & & & & \\
\hline & Coagulate & \multicolumn{2}{|c|}{ Flocculate } & & & & & & & & & \\
\hline 7 & 0 & \multicolumn{2}{|c|}{ Optifloc C6260 } & 6.30 & 1.83 & 1.71 & 0.09 & 1.40 & -- & -- & -- & -- \\
\hline 7 & $\mathrm{Fe}_{2}\left(\mathrm{SO}_{4}\right)_{3}$ & \multicolumn{2}{|c|}{ Optifloc C6260 } & 6.20 & 1.75 & 1.65 & 0.08 & 1.40 & -- & -- & -- & -- \\
\hline 8 & $\mathrm{Fe}_{2}\left(\mathrm{SO}_{4}\right)_{3}$ & \multicolumn{2}{|c|}{ Optifloc C6260 } & 9.50 & 2.81 & 2.59 & 0.08 & 2.00 & -- & -- & -- & -- \\
\hline 8 & $\left(\mathrm{AL}_{2} \mathrm{SO}_{4}\right)_{3}$ & \multicolumn{2}{|c|}{ Optifloc C6260 } & 10.00 & 2.52 & 2.34 & 0.05 & 1.90 & -- & -- & -- & -- \\
\hline 8 & 0 & \multicolumn{2}{|c|}{ Optifloc C6260 } & 6.50 & 1.83 & 1.57 & 0.09 & 1.10 & -- & -- & -- & -- \\
\hline 9 & $\left(\mathrm{AL}_{2} \mathrm{SO}_{4}\right)_{3}$ & \multicolumn{2}{|c|}{ Optifloc C6260 } & 7.00 & 2.55 & 1.71 & 0.09 & 1.40 & 0.03 & 0.0020 & 0.15 & 0.15 \\
\hline
\end{tabular}

The nutrient concentration was significantly lower in the liquid fraction than in the unseparated manure, especially for DM content and for the concentration of nutrients associated with particles, such as $\mathrm{P}, \mathrm{Ca}$, and $\mathrm{Mg}$ (table 5). The concentration of soluble nutrients, such as $\mathrm{K}^{2}$ and $\mathrm{NH}_{4}{ }^{+}$, was also lowered because the dewatering belt was continuously cleaned by washing with water, giving a significant dilution.

\section{Separation Performance in Terms of G-Force}

Full-scale centrifuge experiments were conducted to determine the influence of the centrifuge operating variables on nutrient recovery. The centrifuge operating variables examined were gravitational force (G-force), feed rate, and weir plate diameter. The rotation speed of the centrifuge was changed within the 2000 to $3130 \mathrm{rpm}$ range, resulting in gravitational forces between $1044 G$ and $2558 G$. The separation results versus gravitational force are presented in table 2 . Separation efficiency was, as expected, affected by the gravitational force. It can be seen that increasing amounts of nutrients were transferred to the solid fraction as the gravitational force was increased to approximately $2200 G$, in the case of pig manure 5. However, with pig manure 6 , it seems that increasing the gravitational force beyond $2047 G$ did not improve separation efficiency significantly. The separation efficiency seems rather stable between $2047 G$ and $2558 G$ for nutrients associated with particles, such as $\mathrm{P}, \mathrm{Ca}$, and $\mathrm{Mg}$. However, the amount of solids (solid-to-slurry ratio) is reduced by increasing the gravitational force, as is the separation of nutrients associated with the liquids, such as $\mathrm{NH}_{4}$ and $\mathrm{K}$. The DM content and nutrient concentrations versus gravitational force are presented in figure 3 . It can be seen that DM content and nutrient concentration both increased when the gravitational force was increased to approximately $2200 G$ in the case of pig manure 5 . In the case of pig manure 6 , increasing the gravitational force up to $2558 G$ increased the DM concentration, but nutrient concentrations were barely affected.

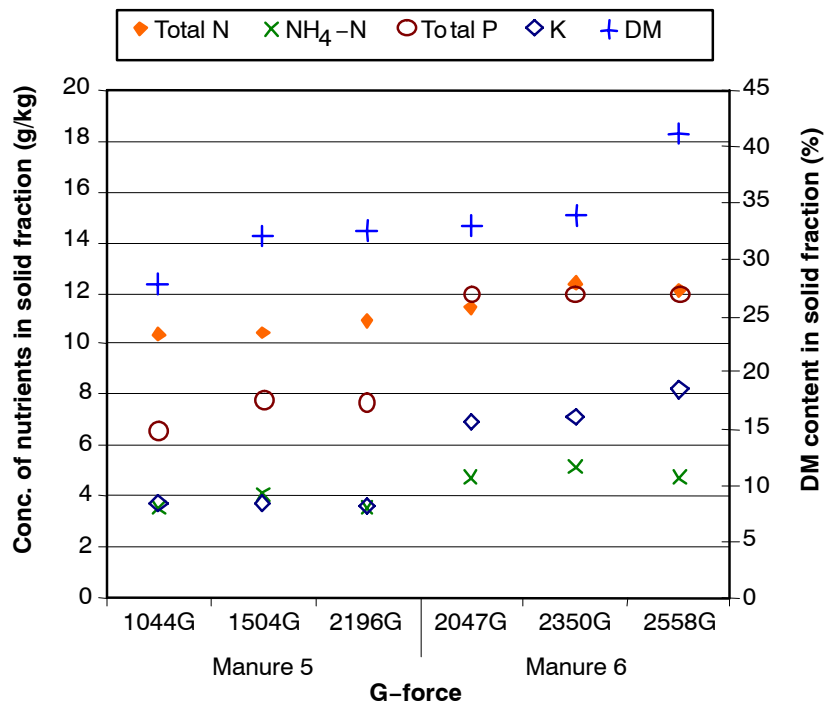

Figure 3. Composition of the solid fraction after separation of pig slurry subjected to different G-forces. Two different manures from fattening pigs were used in the test: manure 5 had a normal dry matter content (6.9\%), and manure 6 had a very high dry matter content $(8.9 \%)$. 


\section{Separation Performance in Terms of Weir Plate DIAMETER}

The dewatering volume of a decanter is considered to be the total content of the liquid zone in the cylindrical part of the drum. This volume changes in relation to the weir plate diameter, so a smaller weir plate diameter will increase both the dewatering volume and retention time (Vanderbeken, 2005). When the retention time is longer, more efficient solid-liquid separation is expected. However, increasing the dewatering volume reduces the retention time in the dewatering zone, which might reduce the dewatering of the solid part.

The following weir plate diameters were tested: 270,280 , and $290 \mathrm{~mm}$. Separation efficiency was found to be affected by changing the weir plate diameter, as increasing amounts of nutrients were transferred to the solid fraction as weir plate diameter was reduced in manure 5 with a constant G-force of $2196 G$ (table 2).

Both the DM content and nutrient concentration increased in solids produced from manure 5 as the weir plate diameter was increased and the retention time in the dewatering zone was increased (table 4) with a constant G-force of $2196 G$. Sneath et al. (1988) found that the DM content of the solid fraction increased when the dewatering volume was reduced, thus increasing the retention time in the dewatering zone. The concentration of nutrients associated with particles, such as $\mathrm{P}$ and $\mathrm{Mg}$, was also increased by increasing the weir plate diameter. However, the nutrient concentration of nutrients associated with liquids, such as $\mathrm{NH}_{4}$ and $\mathrm{K}$, was barely affected. By reducing the flow rate (LF) and using a weir plate of $270 \mathrm{~mm}$ diameter, both the DM content and the concentration of nutrients associated with particles, such as $\mathrm{P}, \mathrm{Ca}$, and $\mathrm{Mg}$, were reduced. There is no obvious reason for this.

\section{Methane Yield from Fractions of Manure Deriving FROM SEPARATION}

Considerable research in developing biogas technology has been done in Denmark, and several co-digestion and farm-scale plants are currently running. However, biogas production from manure in terms of yield per volume is low, and biogas plants depend on a supply of easily degradable waste products to be economically feasible (Nielsen et al., 2002). The development of new centralized plants is currently stagnant due to a limited supply of such waste products. The transport of slurry from the farm to the biogas plant is an important operating cost factor for the co-digestion plants, and it is one reason for the poor economic performance of biogas plants running mainly on manure. By reducing the transport cost per $\mathrm{m}^{3}$ of methane produced and increasing the daily methane production per $\mathrm{m}^{3}$ digester volume, the economic feasibility of co-digestion plants might be improved, as long as separation costs do not exceed the value of added benefits.

Drainage of water from the manure by separation creates a solid fraction with a higher VS concentration, thus producing a manure waste fraction with a higher volumetric biogas potential. Møller et al. (2004) found a methane yield of $194 \mathrm{~L} / \mathrm{kg}$ VS from solids produced by centrifugation and $247 \mathrm{~L} / \mathrm{kg}$ VS from those produced by precipitation and flocculation. This study found that the methane yield from solids separated by chemical precipitation and flocculation was significantly higher than that from solids separated by centrifugation. The yield after 60 days of batch digestion of solids from the centrifugation of pig manure was 161 to $186 \mathrm{~L}$ $\mathrm{CH}_{4} / \mathrm{kg}$ VS, compared to $253 \mathrm{~L} \mathrm{CH}_{4} / \mathrm{kg}$ VS from dairy cow manure (fig. 4). Surprisingly, solids from the centrifugation of dairy cow manure gave a higher yield than did solids from pig manure, although the yield was higher from unseparated pig manure than from unseparated dairy cow manure, indicating that the centrifugation of pig manure gives a poor separation of the small highly digestible particles, while centrifugation of cattle manure to a higher extent separates both highly and slowly digestible particles in the same proportions. The yield from the solids produced by coagulation and flocculation after 60 days of batch digestion was 392 to $404 \mathrm{~L} \mathrm{CH}_{4} / \mathrm{kg}$ VS. There was no significant difference between the yield from solids coagulated with $\mathrm{Fe}$ and that from solids only flocculated with polymer.

The methane yield from the flocculated solids was at the same level or even higher than yields from unseparated

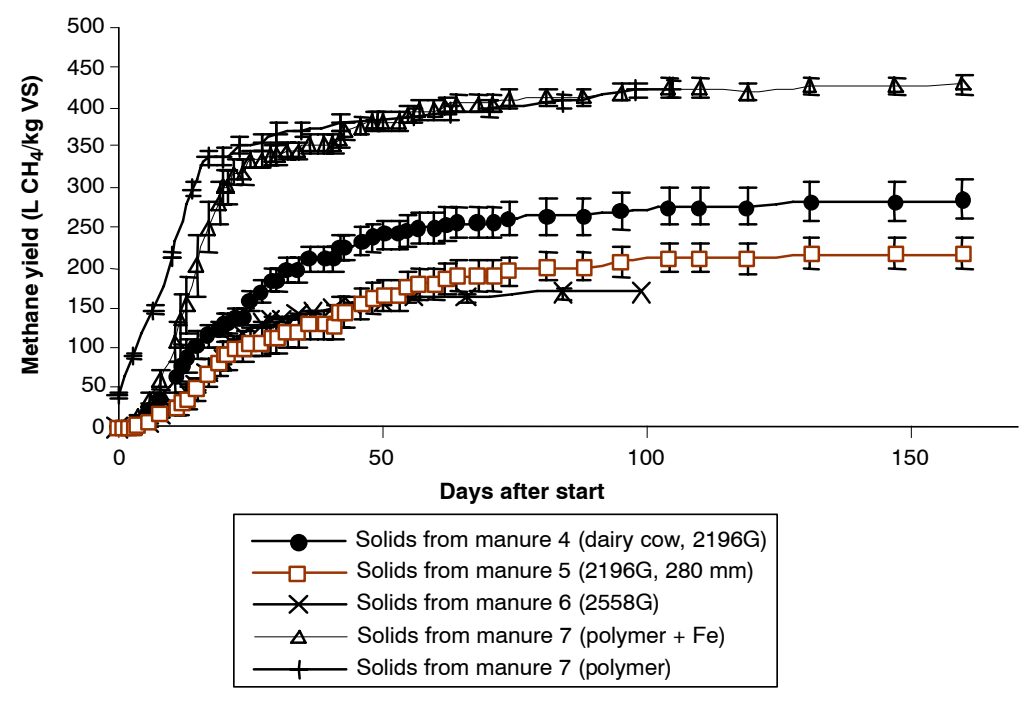

Figure 4. Methane yield of solids separated by centrifugation and chemical treatment, plotted against time (standard deviations indicated by bars). The total VS content in the separated solids from manures 4, 5, 6, 7 (with polymer + Fe), and 7 (with polymer) prior to batch digestion were respectively $160,251,283,112$, and $124 \mathrm{~g} / \mathrm{kg}$. 
manure in terms of VS as found in a previous study (Møller et al., 2004). Since the DM and VS content is 5 to 10 times higher in the solids than in the liquid manure, the solids are very suitable for transport to an anaerobic digestion plant. The methane yield from the centrifuged solids was $40 \%$ to $50 \%$ lower than that from unseparated manure in terms of VS; however, since the VS content is 5 to 15 times higher in the solids than in the liquid manure, the methane yield in terms of the volume of centrifuged solids is still 2 to 7 times higher than that of liquid manure.

\section{Conclusions}

Solid-liquid separation produces nutrient and dry matter rich fractions from liquid manure. Both centrifugation and chemical precipitation and flocculation proved to be efficient separation methods. The efficiency of centrifugation depends on factors such as manure type, G-force, and dewatering volume, while the efficiency of chemical treatment depends on the amount and type of chemicals and polymers used. The centrifuge transferred an increasing amount of nutrients and dry matter to the solid fraction as the gravitational force was increased to approximately $2200 G$; however, increasing the gravitational force beyond $2047 G$ did not improve separation efficiency significantly. The separation efficiencies for total $\mathrm{N}$ and dry matter were highly dependent on the dry matter content of the manure, while the separation efficiency for total $\mathrm{P}$ was little affected by this factor. We used linear regression to determine the relationships between DM content in the manure and the achieved separation efficiencies. The relationships thus found differed from those found by a previous study using a different model centrifuge. This clearly indicates that different centrifuges have different performance and separation characteristics.

The DM content and nutrient concentration both increased when the gravitational force was increased to approximately $2200 G$. However, increasing the gravitational force up to $2558 G$ only increased the $\mathrm{DM}, \mathrm{Mg}$, and $\mathrm{Ca}$ concentrations. When using chemical treatment, the separation efficiencies for dry matter and nutrients varied depending on the different types of manure and of added coagulants and flocculants. The separation efficiencies achieved with chemical treatment were higher than those achieved with centrifugation.

The yield after 60 days of batch digestion of the solids produced by centrifuging pig manure was 161 to $186 \mathrm{~L}$ $\mathrm{CH}_{4} / \mathrm{kg} \mathrm{VS}$, compared to $253 \mathrm{~L} \mathrm{CH}_{4} / \mathrm{kg}$ VS from centrifuged dairy cow manure. Surprisingly, the solids from centrifuged dairy cow manure gave a higher yield than did the solids from pig manure, although the yield in general was higher from unseparated pig manure than from unseparated dairy cow manure in previous studies. The yield from the solids produced by coagulation and flocculation of pig manure, after 60 days of batch digestion, was 392 to $404 \mathrm{~L} \mathrm{CH}_{4} / \mathrm{kg} \mathrm{VS}$. There was no significant difference in terms of methane yield between the solids coagulated with $\mathrm{Fe}$ and those only flocculated with polymer.

This study indicates that solid-liquid separation, especially with addition polymers, has potential for pre-separation of manure before transportation to a co-digestion plant. Preseparation might improve the economical performance, since the methane yield in terms of VS is in the same magnitude as unseparated manure and the VS content is 5 to 10 times higher than in liquid manure, thus significantly reducing the transport cost per unit of VS. However, the increased costs of separation should be taken into account when evaluating the total benefits.

\section{ACKNOWLEDGEMENTS}

Thanks to Frank Bjerregaard Rasmussen (TechRas Miljoe ApS, Silkeborg, Denmark) for making the decanting centrifuge available and for his assistance during the performance of the tests.

\section{REFERENCES}

APHA. 1995. Standard Methods for the Examination of Water and Waste Water. 19th ed. Washington, D.C.: American Public Health Association.

Burton, C. H., and C. Turner. 2003. Manure Management: Treatment Strategies for Sustainable Agriculture. Bedford, U.K.: Silsoe Research Institute.

Krumpelman, B. W., T. C. Daniel, F. G. Edwards, R. W. McNew, and D. M. Miller. 2005. Optimum coagulant and flocculant concentrations for solids and phosphorus removal from pre-screened flushed dairy manure. Applied Eng. in Agric. 21(1): 127-135.

Møller, H. B., I. Lund, and S. G. Sommer. 2000. Solid-liquid separation of livestock slurry: Efficiency and cost. Bioresource Tech. 74(3): 223-229.

Møller, H. B., S. G. Sommer, and B. K. Ahring. 2002. Separation efficiency and particle size distribution in relation to manure type and storage conditions. Bioresource Tech. 85(2): 189-196.

Møller, H. B., B. K. Ahring, and S. G. Sommer. 2004. Methane productivity of manure, straw and solid fractions of manure. Biomass and Bioenergy 26(5): 485-495.

Nielsen, L. H., K. Hjort-Gregersen, P. Thygesen, and J. Christensen. 2002. Samfunds $\varnothing$ konomiske analyser af biogasfallesanlaeg med tekniske og selskabsøkonomiske baggrundsanalyser (Socio-economic analyses of centralized biogas plants). Report No. 136. Frederiksberg, Denmark: Fødevareøkonomisk Institut.

Poulsen, H. D., C. F. Børsting, H. B. Rom, and S. G. Sommer. 2001. Kvaelstof, fosfor og kalium i husdyrgødning - normtal 2000 (Nitrogen, phosphor, and potassium in manure - 2000 norms) DIAS Report No. 36. Viborg, Denmark: Danmarks JordbrugsForskning.

Seadi, T. A., and H. B. Møller. 2003. The future of biogas in Europe II. In European Biogas Workshop. Odense, Denmark: University of Southern Denmark.

Sneath, R. W., M. Shaw, and A. G. Williams. 1988. Centrifugation for separating piggery slurry: I. The performance of a decanting centrifuge. J. Agric. Eng. 39 (3): 181-190.

Steed, J., and G. Hashimoto. 1994. Methane emissions from typical manure management systems. Bioresource Tech. 50(2): 123-130.

Svarovsky, L. 1985. Solid-liquid separation processes and technology. In Handbook of Powder Technology, 5: 18-22. J. C. Williams and T. Allen, eds. London, U.K.: Butterworth.

Timby, G. G., T. C. Daniel, R. W. McNew, and P. A. Moore, Jr. 2004. Polymer type and aluminum chloride affect solids and phosphorus removal from flushed dairy slurry. Applied Eng. in Agric. 29(1): 57-64.

Vanderbeken. 2005. Separation by centrifugation. White Rock, British Columbia: Vanderbeken Enterprises, Ltd.Available at: www.sewage.net.

Zhang, R. H., and F. Lei. 1998. Chemical treatment of animal manure for solid liquid separation. Trans. ASAE 41(4): 1103-1108. 